\title{
Algoritma K-Means Untuk Mengelompokkan Suplier Obat (Studi Kasus: RS. Prima Husada Cipta Medan)
}

\author{
K-Means Algorithm for Grouping Drug Suppliers (Case Study : RS. Prima Husada Cipta Medan) \\ Fahdin Zikri ${ }^{1}$, Fina Nasari ${ }^{2}$ \\ 1,2 Program Studi Sistem Informasi, Fakultas Teknik dan Ilmu Komputer \\ Universitas Potensi Utama, Jl.K.L. Yos Sudarso KM 6.5 Tanjung Mulia-Medan \\ E-mail:fahdinzikri8@gmail.com ${ }^{1}$, finanasari@gmail.com ${ }^{2}$
}

\begin{abstract}
ABSTRAK
Obat merupakan zat yang berasal dari tumbuhan, hewan, mineral maupun zat kimia tertentu yang dapat digunakan untuk mengurangi rasa sakit, memperlambat proses penyakit dan atau menyembuhkan penyakit. Obat-obat yang diterima oleh RS. Prima Husada Cipta Medan merupakan obat yang telah dikirimkan oleh suplier-suplier nya. Dengan banyaknya data tersebut, maka bagian Farmasi RS. Prima Husada Cipta Medan mengalami kesulitan untuk menentukan tingkat pengiriman terhadap masing-masing supplier. Dari permasalahan yang ada, maka penulis ingin menerapkan data mining dengan algoritma K-Means (Clustering) menggunakan aplikasi RapidMiner untuk mengelompokkan data supplier, yang awalnya tidak tersusun/terstruktur bisa menjadi data yang terstruktur, selain itu penggalian informasi pada sebuah data yang berukuran sangat besar (memiliki jumlah field dan jumlah record yang banyak) tidak dapat dilakukan dengan mudah, maka daripada itu teknologi data mining adalah salah satu alat bantu untuk penggalian data berukuran besar dengan tingkat kerumitan yang cukup mudah. Pengolahan data mining yang dilakukan pada penelitian ini menggunakan tahapan Knowledge Discovery in Database (KDD), agar dapat menghasilkan informasi sesuai dengan tahapan yang telah ditentukan. Penelitian ini juga menggunakan tools RapidMiner agar dapat dilakukannya pengujian dengan perhitungan manual dan dengan menggunakan tools RapidMiner. Hasil akhir dari penelitian ini berbentuk informasi mengenai tingkat pengiriman dari para supplier yang terbagi menjadi 3 kelompok pengiriman yaitu tinggi, sedang, dan rendah.
\end{abstract}

Kata Kunci : Data mining, Algoritma K-Means, Supplier, Clustering

ABSTRACT

Medicines are substances derived from plants, animals, minerals or certain chemicals that can be used to reduce pain, slow down the disease process and / or cure disease. Drugs received by the Prima Husada Cipta Medan Hospital are a medicine that has been sent by its suppliers. With so much data, the Prima Husada Cipta Medan Hospital Pharmacy section has difficulty in determining the level of delivery for each supplier. From the existing problems, the authors want to apply data mining with the K-Means algorithm (Clustering) using the Rapid Miner application to group supplier data, which initially is not structured to be structured data, besides extracting information on a very large data (having a large number of fields and a large number of records) cannot be done easily, therefore data mining technology is one of the tools for extracting large data with a fairly easy level of complexity. Data mining processing carried out in this study uses the Knowledge Discovery in Database (KDD) stage, in order to produce information in accordance with predetermined stages. This research also uses Rapid Miner tools so that testing can be done with manual calculations and by using the Rapid Miner tools. The final result of this study is in the form of information about the delivery rate from suppliers which are divided into 3 delivery groups, namely high, medium, and low.

Keywords: Data mining, K-Means Algorithm, Supplier, Clustering 


\section{PENDAHULUAN}

Pemasok yaitu suatu perusahaan atau individu yang bertujuan untuk menyediakan sumber daya yang dibutuhkan oleh perusahaan agar dimanfaatkan dalam memproduksi barang dan jasa[1].

Obat merupakan zat yang berasal dari tumbuhan, hewan, mineral maupun campuran zat kimia tertentu yang biasa digunakan untuk mengurangi rasa sakit, memperlambat proses dari reaksi penyakit dan menyembuhkan berbagai penyakit[2]. Namun untuk seorang dokter, ilmu ini dibatasi tujuannya yaitu agar dapat menggunakan obat untuk maksud pencegahan, diagnosis, dan pengobatan penyakit. Selain itu penggunaan obat yang berlebihan atau tidak sesuai dengan resep dokter dapat mengakibatkan berbagai jenis penyakit.

Obat-obat yang diterima oleh RS. Prima Husada Cipta Medan merupakan obat yang telah dikirimkan oleh suplier-suplier nya. Supplier dapat mengirimkan obat hasil produksinya dengan nama yang sama berkali-kali dalam beberapa bulan, maka dari itu bagian Farmasi RS. Prima Husada Cipta Medan melakukan rekapitulasi data-data transaksi terhadap para supplier yang mengirimkan obat-obatnya dengan cara mengelompokkan data supplier tersebut berdasarkan jenis obat dan total keuangan. Dengan banyaknya data tersebut, maka bagian Farmasi RS. Prima Husada Cipta Medan mengalami kesulitan untuk menentukan tingkat pengiriman terhadap masing-masing supplier.

Pada penelitian terdahulu yang dilakukan oleh Elmayati, 2017. Menjelaskan bahwa Dari hasil penelitian yang telah dilakukan penulis di Klinik Srikandi Medika maka kesimpulannya bahwa hasil dari metode clustering data mining dapat digunakan untuk mengetahui kelompok obat yang paling laris dan tidak laris pada Klinik Srikandi Medika, sehingga apabila akan dilakukan pengadaan persediaan obat, petugas dapat melihat daftar obat dengan penjualan terlaris[3].

Penelitian yang dilakukan oleh Fina Nasari dan Surya Darma, 2015 menyimpulkan bahwa dari hasil penelitian yang telah dilakukan, penulis dapat menarik beberapa kesimpulan, antara lain Pengujian yang dilakukan dalam penelitian ini, iterasi clustering data pad mahasiswa terjadi sebanyak 2 kali iterasi, dari Pengujian yang dilakukan ditemukan pusat cluster dengan Cluster $1=$ $1 ; 1.75 ; 1.5$ dan Cluster $2=2.907216495 ; 1.654639175 ; 1.474226804$, Berdasarkan dari hasil tersebut kesimpulan yang didapat bahwa jika asal sekolah pada mahasiswa adalah SMA maka ratarata jurusan yang diambil adalah Sistem Informasi dan jika asal sekolah pada mahasiswa adalah SMK maka rata-rata jurusan yang diambil adalah Teknik Informatika, Hasil cluster juga dipengaruhi dari nilai centroid awal yang dipakai dan jumlah data yang dipakai, perbedaan pengambilan data pusat centroid awal yang dipakai juga akan mempengaruhi hasil cendroid akhirnya[4].

Penelitian yang dilakukan oleh Randi Rian Putra dan Cendra Wadisman, 2018 mendapatkan kesimpulan bahwa mengelompokkan data dengan menggunakan algoritma K-Means dapat dilakukan dengan cara menentukan jumlah cluster, dan menghitung jarak terdekat dengan pusat cluster[5].

\section{METODE PENELITIAN}

Di bawah ini adalah diagram alir penelitian yang akan dilaksanakan oleh penulis. Diagram alir penelitian ini dapat dilihat pada gambar 1 berikut : 


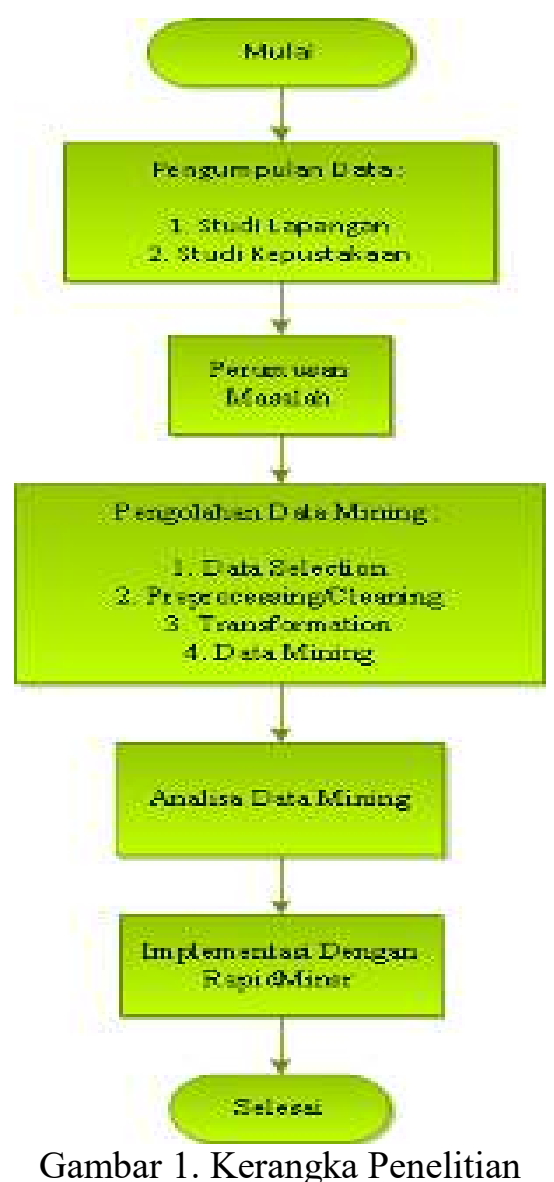

\section{HASIL DAN PEMBAHASAN}

\subsection{Pembahasan}

Untuk mempermudah dalam perhitungan data mining, penulis menggabungkan beberapa variabel menjadi satu, contohnya Bulan 1 sampai dengan Bulan 12 dijumlahkan hingga menghasilkan satu variabel yaitu $\mathrm{X}$.

Tabel 1. Data Rekap Penerimaan Barang Gudang Farmasi

\begin{tabular}{|c|l|c|}
\hline NO & \multicolumn{1}{|c|}{ NAMA PBF } & X \\
\hline 1 & PT. ANTAR MITRA SEMBADA & 38 \\
\hline 2 & PT. ANUGERAH PHARMINDO LESTARI & 68 \\
\hline 3 & PT. ANUGERAH ARGON MEDICA & 86 \\
\hline 4 & PT. ANUGERAH REZEKI BERSAMA & 21 \\
\hline 5 & PT. BERJAYA TANGGUH & 12 \\
\hline 6 & PT. BERJAYA TEGUH ABADI & 12 \\
\hline 7 & PT. BINA SAN PRIMA & 56 \\
\hline 8 & PT. BINTANG SAUDARA & 11 \\
\hline 9 & PT. BRATACO & 12 \\
\hline 10 & PT. DAYA MUDA AGUNG & 21 \\
\hline 11 & PT. DELI KARYA PRIMA & 32 \\
\hline 12 & PT. DIMAS ANDALAS MAKMUR & 18 \\
\hline 13 & PT. DISTRIVERSA BUANA MAS & 33 \\
\hline 14 & PT. DOS NI ROHA & 25 \\
\hline 15 & PT. ENSEVAL MEGATRADING & 12 \\
\hline 16 & PT. GARUDA PERKASA INDONESIA & \\
\hline
\end{tabular}




\begin{tabular}{|c|l|c|}
\hline NO NAMA PBF & X \\
\hline 17 & PT. GLOBAL MITRA PRIMA & 12 \\
\hline 18 & PT. HEXALAB SUMATERA & 12 \\
\hline 19 & PT. INDOFARMA GLOBAL & 16 \\
\hline 20 & PT. KALISTA PRIMA & 82 \\
\hline 21 & PT. KEBAYORAN FARMA & 12 \\
\hline 22 & PT. KIMIA FARMA & 14 \\
\hline 23 & PT. MENSA BUANA SUKSES & 12 \\
\hline 24 & PT. MERAPI UTAMA PHARMA & 21 \\
\hline 25 & PT. MILENIUM FARMA & 12 \\
\hline 26 & PT. MULTIPLUST MEDILAB & 20 \\
\hline 27 & PT. PARIT PADANG GLOBAL & 12 \\
\hline 28 & PT. PENTA VALENT & 21 \\
\hline 29 & PT. RAJAWALI & 12 \\
\hline 30 & PT. SAPTA SARI TAMA & 12 \\
\hline 31 & PT. SEKARGUNA & 13 \\
\hline 32 & PT. TEMPO & 12 \\
\hline 33 & PT. TIRTA MEDICAL INDONESIA & 12 \\
\hline 34 & PT. TRI SAPTA JAYA & 16 \\
\hline 35 & PT. UNITED DICO CITAS & 12 \\
\hline 36 & APT. DELIMA MARTUBUNG & 12 \\
\hline 37 & APT. ERA BELAWAN & 12 \\
\hline 38 & APT. HIDUP SEHAT & 12 \\
\hline 39 & APT. K 24 M YAMIN & 12 \\
\hline 40 & APT. KF BELAWAN & 12 \\
\hline 41 & APT. KF MARELAN & 12 \\
\hline 42 & APT. KF SIANTAR & 12 \\
\hline 43 & APT. MANDIRI & 12 \\
\hline 44 & APT. MARY 3 & 12 \\
\hline 45 & APT. MEDAN & 12 \\
\hline 46 & APT. MERPATI & 12 \\
\hline 47 & APT. MESTIKA & 12 \\
\hline 48 & APT. NEO SEGAR & 12 \\
\hline 49 & APT. PRIMA KRAKATAU & 12 \\
\hline 50 & APT. RAYA & 12 \\
\hline 51 & APT. YAKIN SEHAT & 12 \\
\hline 52 & TOKO ALKES AINI & 12 \\
\hline 53 & TOKO ALKES METRUM & 12 \\
\hline 54 & KANTOR KESEHATAN BELAWAN & 12 \\
\hline 55 & RS. MITRA MEDICA & 12 \\
\hline 56 & RSU. PRINGADI & 12 \\
\hline 57 & RSU. ROYAL PRIMA & 12 \\
\hline 58 & RSU. WULAN WINDI & 12 \\
\hline & & 12 \\
\hline
\end{tabular}

Pengujian algoritma $k$-means yang telah di rancang dengan melakukan penghitungan secara manual dari data set yang telah di transformasikan sesuai dengan langkah-langkah algoritma $k$ means. Penulis telah memilih centroid secara acak yakni PT. ANUGERAH PHARMINDO LESTARI sebagai centroid 1 (C1), lalu PT. DIMAS ANDALAS MAKMUR sebagai centroid 2 (C2), dan PT. MULTIPLUST MEDILAB sebagai centroid 3 (C3). Adapun penghitungan yang dimaksud adalah sebagai berikut : 
A. Iterasi 1

1) Langkah pertama, temukan cluster yang paling dekat dengan pusat cluster menggunakan rumus Euclidean Distance Space.

Tabel 2. Hasil Perhitungan Jarak Setiap Data Untuk Masing-masing Cluster dan Penentuan Kelompok Terdekat Iterasi 1

\begin{tabular}{|c|c|c|c|}
\hline NO & NAMA PBF & $\mathrm{X}$ & GRUP \\
\hline 1 & PT. ANTAR MITRA SEMBADA & 38 & B \\
\hline 2 & PT. ANUGERAH PHARMINDO LESTARI & 68 & A \\
\hline 3 & PT. ANUGERAH ARGON MEDICA & 86 & A \\
\hline 4 & PT. ANUGERAH REZEKI BERSAMA & 21 & $\mathrm{C}$ \\
\hline 5 & PT. BERJAYA TANGGUH & 12 & $\mathrm{C}$ \\
\hline 6 & PT. BERJAYA TEGUH ABADI & 12 & $\mathrm{C}$ \\
\hline 7 & PT. BINA SAN PRIMA & 56 & A \\
\hline 8 & PT. BINTANG SAUDARA & 11 & $\mathrm{C}$ \\
\hline 9 & PT. BRATACO & 12 & $\mathrm{C}$ \\
\hline 10 & PT. DAYA MUDA AGUNG & 13 & $\mathrm{C}$ \\
\hline 11 & PT. DELI KARYA PRIMA & 21 & $\mathrm{C}$ \\
\hline 12 & PT. DIMAS ANDALAS MAKMUR & 32 & $\mathrm{~B}$ \\
\hline 13 & PT. DISTRIVERSA BUANA MAS & 18 & $\mathrm{C}$ \\
\hline 14 & PT. DOS NI ROHA & 33 & $\mathrm{~B}$ \\
\hline 15 & PT. ENSEVAL MEGATRADING & 25 & $\mathrm{~B}$ \\
\hline 16 & PT. GARUDA PERKASA INDONESIA & 12 & $\mathrm{C}$ \\
\hline 17 & PT. GLOBAL MITRA PRIMA & 12 & $\mathrm{C}$ \\
\hline 18 & PT. HEXALAB SUMATERA & 12 & $\mathrm{C}$ \\
\hline 19 & PT. INDOFARMA GLOBAL & 16 & $\mathrm{C}$ \\
\hline 20 & PT. KALISTA PRIMA & 82 & A \\
\hline 21 & PT. KEBAYORAN FARMA & 12 & $\mathrm{C}$ \\
\hline 22 & PT. KIMIA FARMA & 14 & $\mathrm{C}$ \\
\hline 23 & PT. MENSA BUANA SUKSES & 12 & $\mathrm{C}$ \\
\hline 24 & PT. MERAPI UTAMA PHARMA & 43 & $\mathrm{~B}$ \\
\hline 25 & PT. MILENIUM FARMA & 21 & $\mathrm{C}$ \\
\hline 26 & PT. MULTIPLUST MEDILAB & 12 & $\mathrm{C}$ \\
\hline 27 & PT. PARIT PADANG GLOBAL & 20 & $\mathrm{C}$ \\
\hline 28 & PT. PENTA VALENT & 12 & $\mathrm{C}$ \\
\hline 29 & PT. RAJAWALI & 21 & $\mathrm{C}$ \\
\hline 30 & PT. SAPTA SARI TAMA & 12 & $\mathrm{C}$ \\
\hline 31 & PT. SEKARGUNA & 12 & $\mathrm{C}$ \\
\hline 32 & PT. TEMPO & 13 & $\mathrm{C}$ \\
\hline 33 & PT. TIRTA MEDICAL INDONESIA & 12 & $\mathrm{C}$ \\
\hline 34 & PT. TRI SAPTA JAYA & 12 & $\mathrm{C}$ \\
\hline 35 & PT. UNITED DICO CITAS & 16 & $\mathrm{C}$ \\
\hline 36 & APT. DELIMA MARTUBUNG & 12 & $\mathrm{C}$ \\
\hline 37 & APT. ERA BELAWAN & 12 & $\mathrm{C}$ \\
\hline 38 & APT. HIDUP SEHAT & 12 & $\mathrm{C}$ \\
\hline 39 & APT. K 24 M YAMIN & 12 & $\mathrm{C}$ \\
\hline 40 & APT. KF BELAWAN & 12 & $\mathrm{C}$ \\
\hline 41 & APT. KF MARELAN & 12 & $\mathrm{C}$ \\
\hline 42 & APT. KF SIANTAR & 12 & $\mathrm{C}$ \\
\hline 43 & APT. MANDIRI & 12 & $\mathrm{C}$ \\
\hline 44 & APT. MARY 3 & 12 & $\mathrm{C}$ \\
\hline 45 & APT. MEDAN & 12 & $\mathrm{C}$ \\
\hline 46 & APT. MERPATI & 12 & $\mathrm{C}$ \\
\hline
\end{tabular}




\begin{tabular}{|c|l|c|c|}
\hline NO & \multicolumn{1}{|c|}{ NAMA PBF } & X & GRUP \\
\hline 47 & APT. MESTIKA & 12 & $\mathrm{C}$ \\
\hline 48 & APT. NEO SEGAR & 12 & $\mathrm{C}$ \\
\hline 49 & APT. PRIMA KRAKATAU & 12 & $\mathrm{C}$ \\
\hline 50 & APT. RAYA & 12 & $\mathrm{C}$ \\
\hline 51 & APT. YAKIN SEHAT & 12 & $\mathrm{C}$ \\
\hline 52 & TOKO ALKES AINI & 12 & $\mathrm{C}$ \\
\hline 53 & TOKO ALKES METRUM & 12 & $\mathrm{C}$ \\
\hline 54 & KANTOR KESEHATAN BELAWAN & 12 & $\mathrm{C}$ \\
\hline 55 & RS. MITRA MEDICA & 12 & $\mathrm{C}$ \\
\hline 56 & RSU. PRINGADI & 12 & $\mathrm{C}$ \\
\hline 57 & RSU. ROYAL PRIMA & 12 & $\mathrm{C}$ \\
\hline 58 & RSU. WULAN WINDI & 12 & $\mathrm{C}$ \\
\hline
\end{tabular}

Berikut adalah sedikit penjelasan dari hasil pada Table 2:

PT. ANTAR MITRA SEMBADA ke $\mathrm{C} 1=\sqrt{(38-68)^{2}}=30.0$

PT. ANTAR MITRA SEMBADA ke C2 $=\sqrt{(38-32)^{2}}=6.0$

PT. ANTAR MITRA SEMBADA ke C3 $=\sqrt{(38-12)^{2}}=26.0$

2) Menghitung Centroid

Dari Table 2 dapat dilihat jumlah anggota dari setiap cluster, di mana cluster $1(\mathrm{~A})=4$, cluster $2(\mathrm{~B})=5$, cluster $3(\mathrm{C})=49$. Pada iterasi 1 ini akan didapatkan nilai centroid yang baru dengan menggunakan rumus :

$$
\begin{aligned}
& C=\frac{\sum m}{n} \\
& \mathrm{C} 1(\mathrm{~A})=\frac{(68+86+56+82)}{4}=73.00 \\
& \mathrm{C} 2(\mathrm{~B})=\frac{(38+32+33+25+43)}{5}=34.20 \\
& \mathrm{C} 3(\mathrm{C})=
\end{aligned}
$$

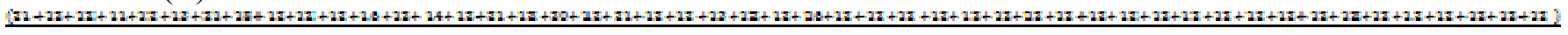

$$
=13.24
$$

Dari perhitungan di atas diperoleh centroid baru dari iterasi 1 ini sebagai berikut :

$\mathrm{C} 1=[73.00], \mathrm{C} 2=[34.20], \mathrm{C} 3=[13.24]$

B. Iterasi 2

Pada iterasi ke-2 ini, langkah selanjutnya adalah mengulangi langkah sebelumnya yaitu :

1) Temukan cluster yang paling dekat dengan pusat cluster dari nilai centroid iterasi 1 yaitu $\mathrm{C} 1$

$=[73.00], \mathrm{C} 2=[34.20], \mathrm{C} 3=$ [13.24] menggunakan rumus Euclidean Distance Space.

Tabel 3. Hasil Perhitungan Jarak Setiap Data Untuk Masing-masing Cluster dan Penentuan Kelompok Terdekat Iterasi 2

\begin{tabular}{|c|l|c|c|}
\hline NO & \multicolumn{1}{|c|}{ NAMA PBF } & X & GRUP \\
\hline 1 & PT. ANTAR MITRA SEMBADA & 38 & B \\
\hline 2 & PT. ANUGERAH PHARMINDO LESTARI & 68 & A \\
\hline 3 & PT. ANUGERAH ARGON MEDICA & 86 & A \\
\hline 4 & PT. ANUGERAH REZEKI BERSAMA & 21 & $\mathrm{C}$ \\
\hline 5 & PT. BERJAYA TANGGUH & 12 & $\mathrm{C}$ \\
\hline 6 & PT. BERJAYA TEGUH ABADI & 12 & $\mathrm{C}$ \\
\hline 7 & PT. BINA SAN PRIMA & 56 & $\mathrm{~A}$ \\
\hline 8 & PT. BINTANG SAUDARA & 11 & $\mathrm{C}$ \\
\hline 9 & PT. BRATACO & 12 & $\mathrm{C}$ \\
\hline
\end{tabular}




\begin{tabular}{|c|c|c|c|}
\hline NO & NAMA PBF & $\mathrm{X}$ & GRUP \\
\hline 10 & PT. DAYA MUDA AGUNG & 13 & $\mathrm{C}$ \\
\hline 11 & PT. DELI KARYA PRIMA & 21 & $\mathrm{C}$ \\
\hline 12 & PT. DIMAS ANDALAS MAKMUR & 32 & $\mathrm{~B}$ \\
\hline 13 & PT. DISTRIVERSA BUANA MAS & 18 & $\mathrm{C}$ \\
\hline 14 & PT. DOS NI ROHA & 33 & B \\
\hline 15 & PT. ENSEVAL MEGATRADING & 25 & $\mathrm{~B}$ \\
\hline 16 & PT. GARUDA PERKASA INDONESIA & 12 & $\mathrm{C}$ \\
\hline 17 & PT. GLOBAL MITRA PRIMA & 12 & $\mathrm{C}$ \\
\hline 18 & PT. HEXALAB SUMATERA & 12 & $\mathrm{C}$ \\
\hline 19 & PT. INDOFARMA GLOBAL & 16 & $\mathrm{C}$ \\
\hline 20 & PT. KALISTA PRIMA & 82 & A \\
\hline 21 & PT. KEBAYORAN FARMA & 12 & $\mathrm{C}$ \\
\hline 22 & PT. KIMIA FARMA & 14 & $\mathrm{C}$ \\
\hline 23 & PT. MENSA BUANA SUKSES & 12 & $\mathrm{C}$ \\
\hline 24 & PT. MERAPI UTAMA PHARMA & 43 & $\mathrm{~B}$ \\
\hline 25 & PT. MILENIUM FARMA & 21 & $\mathrm{C}$ \\
\hline 26 & PT. MULTIPLUST MEDILAB & 12 & $\mathrm{C}$ \\
\hline 27 & PT. PARIT PADANG GLOBAL & 20 & $\mathrm{C}$ \\
\hline 28 & PT. PENTA VALENT & 12 & $\mathrm{C}$ \\
\hline 29 & PT. RAJAWALI & 21 & $\mathrm{C}$ \\
\hline 30 & PT. SAPTA SARI TAMA & 12 & $\mathrm{C}$ \\
\hline 31 & PT. SEKARGUNA & 12 & $\mathrm{C}$ \\
\hline 32 & PT. TEMPO & 13 & $\mathrm{C}$ \\
\hline 33 & PT. TIRTA MEDICAL INDONESIA & 12 & $\mathrm{C}$ \\
\hline 34 & PT. TRI SAPTA JAYA & 12 & $\mathrm{C}$ \\
\hline 35 & PT. UNITED DICO CITAS & 16 & $\mathrm{C}$ \\
\hline 36 & APT. DELIMA MARTUBUNG & 12 & $\mathrm{C}$ \\
\hline 37 & APT. ERA BELAWAN & 12 & $\mathrm{C}$ \\
\hline 38 & APT. HIDUP SEHAT & 12 & $\mathrm{C}$ \\
\hline 39 & APT. K 24 M YAMIN & 12 & $\mathrm{C}$ \\
\hline 40 & APT. KF BELAWAN & 12 & $\mathrm{C}$ \\
\hline 41 & APT. KF MARELAN & 12 & $\mathrm{C}$ \\
\hline 42 & APT. KF SIANTAR & 12 & $\mathrm{C}$ \\
\hline 43 & APT. MANDIRI & 12 & $\mathrm{C}$ \\
\hline 44 & APT. MARY 3 & 12 & $\mathrm{C}$ \\
\hline 45 & APT. MEDAN & 12 & $\mathrm{C}$ \\
\hline 46 & APT. MERPATI & 12 & $\mathrm{C}$ \\
\hline 47 & APT. MESTIKA & 12 & $\mathrm{C}$ \\
\hline 48 & APT. NEO SEGAR & 12 & $\mathrm{C}$ \\
\hline 49 & APT. PRIMA KRAKATAU & 12 & $\mathrm{C}$ \\
\hline 50 & APT. RAYA & 12 & $\mathrm{C}$ \\
\hline 51 & APT. YAKIN SEHAT & 12 & $\mathrm{C}$ \\
\hline 52 & TOKO ALKES AINI & 12 & $\mathrm{C}$ \\
\hline 53 & TOKO ALKES METRUM & 12 & $\mathrm{C}$ \\
\hline 54 & KANTOR KESEHATAN BELAWAN & 12 & $\mathrm{C}$ \\
\hline 55 & RS. MITRA MEDICA & 12 & $\mathrm{C}$ \\
\hline 56 & RSU. PRINGADI & 12 & $\mathrm{C}$ \\
\hline 57 & RSU. ROYAL PRIMA & 12 & $\mathrm{C}$ \\
\hline 58 & RSU. WULAN WINDI & 12 & $\mathrm{C}$ \\
\hline
\end{tabular}

Berikut adalah sedikit penjelasan dari hasil pada Table 3 : 


$$
\begin{aligned}
& \text { PT. ANTAR MITRA SEMBADA ke C1 }=\sqrt{(38-73.00)^{2}}=35.0 \\
& \text { PT. ANTAR MITRA SEMBADA ke C2 }=\sqrt{(38-34.20)^{2}}=3.8 \\
& \text { PT. ANTAR MITRA SEMBADA ke C } 3=\sqrt{(38-13.24)^{2}}=24.8
\end{aligned}
$$

Karena pada iterasi ke-1 dan ke-2 posisi cluster tidak berubah, maka iterasi dihentikan dan hasil akhir yang diperoleh adalah 3 cluster dan proses perhitungan pengelompokan supplier berakhir pada tahap iterasi ke 2 .

\section{Implementasi Dengan RapidMiner}

Hasil dari proses data mining yang berupa pola informasi perlu ditampilkan dalam bentuk yang mudah dipahami oleh pihak terkait.

1) Berikut adalah tampilan awal Tools Rapidminer

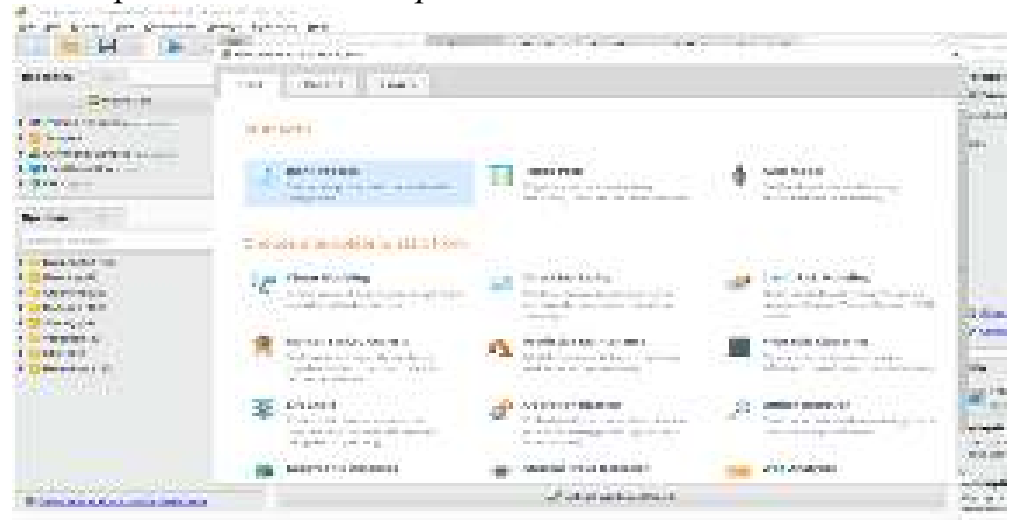

Gambar 2. Tampilan Awal Tools Rapidminer

2) Pilih "Blank" untuk masuk ke tampilan selanjutnya yaitu worksheet

3) Setelah itu "Import" data yang akan digunakan, bisa berupa file Excel

4) Berikut bentuk data setelah dipilih untuk diimport ke dalam Rapidminer

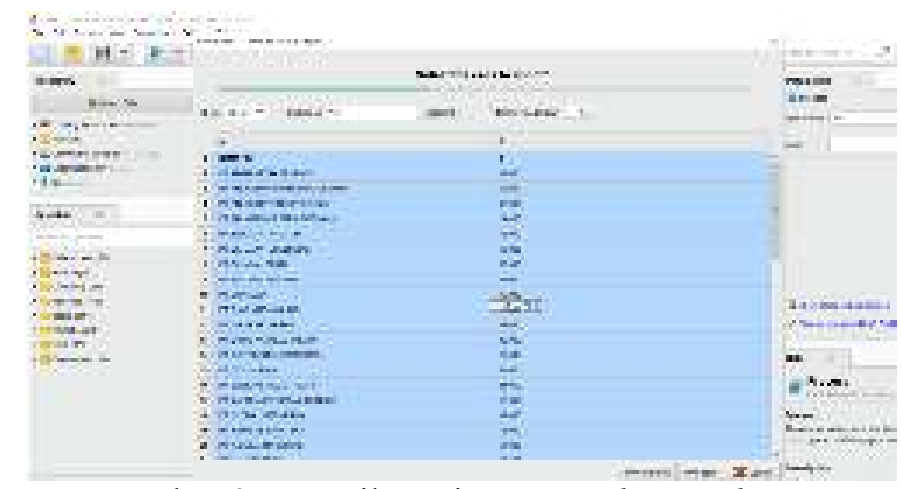

Gambar 3. Tampilan Isi Data Tools Rapidminer

5) Setelah itu, masukkan item-item yang sesuai dengan yang ada di tampilan dengan menyeret item tersebut dari sebelah kiri bawah tampilan RapidMiner, kemudian klik tombol Run 


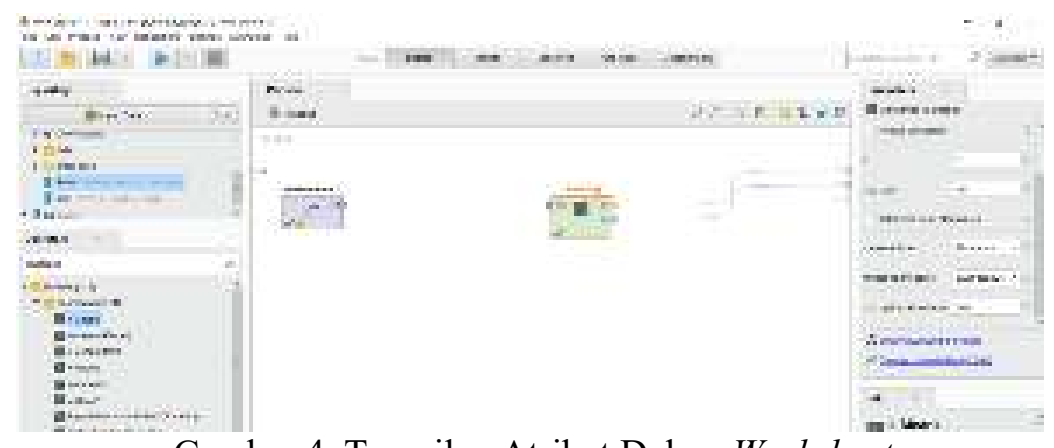

Gambar 4. Tampilan Atribut Dalam Worksheet

6) Setelah diklik tombol Run, maka akan muncul tampilan seperti gambar di bawah ini

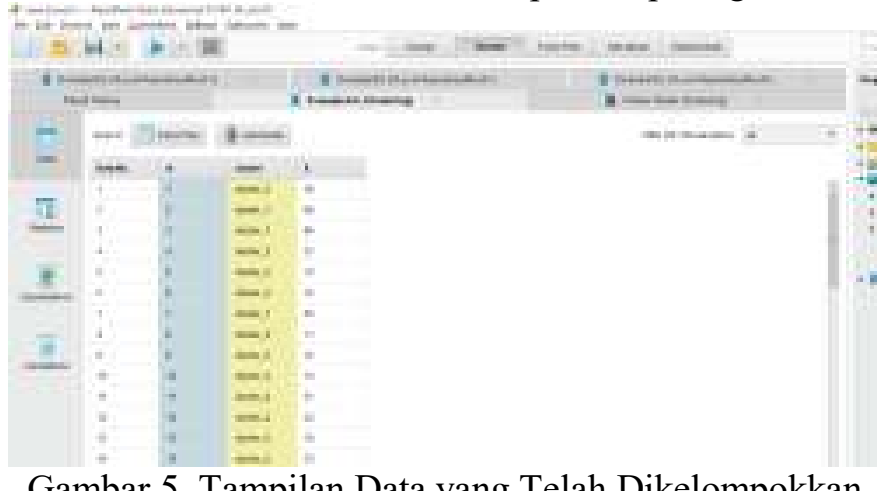

Gambar 5. Tampilan Data yang Telah Dikelompokkan

7) Tampilan jumlah item dari tiap-tiap cluster

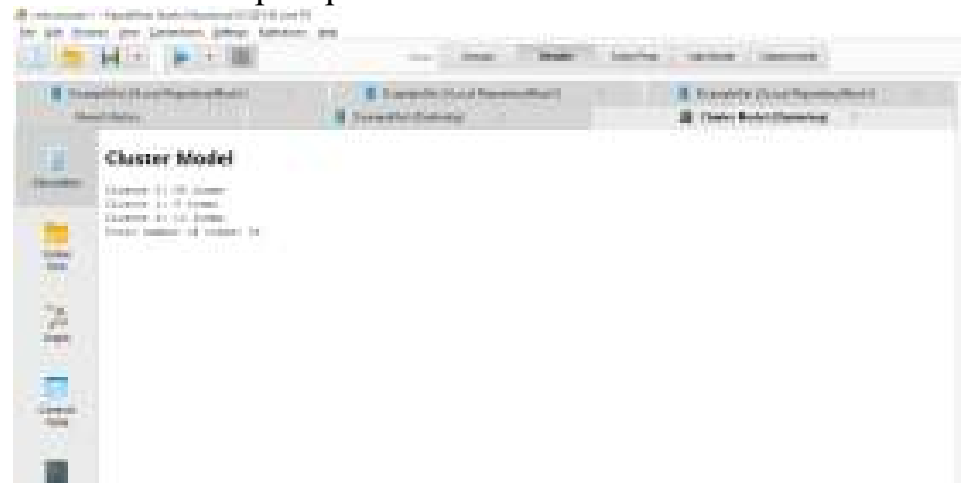

Gambar 6. Tampilan Data yang Telah Dikelompokkan

Berikut adalah jumlah item dari setiap cluster setelah dilakukan nya perhitungan menggunakan algoritma k-means clustering. Dari implementasi rapidminer di atas, penulis mendapatkan hasil dari perhitungan clustering pada rekap penerimaan barang gudang farmasi, bahwa :

1. Cluster 1 (cluster 0$)$, mempunyai anggota yang berjumlah 44 item

2. Cluster 2 (cluster 1), mempunyai anggota yang berjumlah 4 item

3. Cluster 3 (cluster 2), mempunyai anggota yang berjumlah 10 item

\subsection{Hasil}

3.2.1. Pengujian Perhitungan Manual

Dari perhitungan manual, penulis mendapatkan bahwa perhitungan untuk menemukan cluster yang paling dekat dengan pusat cluster hanya mencapai iterasi ke-2. Dari keterangan tersebut penulis merangkum bahwa cluster 1 (A) memiliki 4 anggota, cluster 2 (B) memiliki 5 anggota, dan cluster 3 (C) memiliki 49 anggota.

3.2.2. Pengujian Perhitungan Menggunakan Tools RapidMiner 
Pada pengujian ini, penulis menggunakan tools rapidminer untuk mendapatkan hasil yang efektif. Dari perhitungan menggunakan tools rapidminer penulis mendapatkan hasil yang sedikit berbeda dibandingkan dengan perhitungan manual, yaitu cluster 1 (cluster 0) memiliki 44 item, cluster 2 (cluster 1) memiliki 4 anggota, dan cluster 3 (cluster 2) memiliki 10 item.

\subsubsection{Hasil Pengujian}

Berdasarkan hasil dari perhitungan manual dan perhitungan menggunakan tools rapidminer, penulis menyimpulkan bahwa adanya sedikit perbedaan dari kedua hasil tersebut, pada perhitungan manual cluster 1 memiliki 4 anggota, cluster 2 memiliki 5 anggota, dan cluster 3 memiliki 49 anggota. Sedangkan pada perhitungan menggunakan tools rapidminer cluster 1 memiliki 44 anggota, cluster 2 memiliki 4 anggota, dan cluster 3 memiliki 10 anggota

\section{KESIMPULAN}

Kesimpulan yang didapat dari perhitungan manual dan dengan menggunakan tools RapidMiner adalah bahwa :

1. Dari perhitungan manual, penulis menemukan cluster yang paling dekat dengan pusat cluster hanya mencapai iterasi ke-2. Dari keterangan tersebut penulis merangkum bahwa cluster 1 (A) memiliki 4 anggota, cluster 2 (B) memiliki 5 anggota, dan cluster 3 (C) memiliki 49 anggota,

2. Sedangkan dari perhitungan menggunakan tools RapidMiner penulis mendapatkan hasil yang sedikit berbeda dibandingkan dengan perhitungan manual, yaitu cluster 1 (cluster 0 ) memiliki 44 anggota, cluster 2 (cluster 1) memiliki 4 anggota, dan cluster 3 (cluster 2) memiliki 10 anggota.

\section{SARAN}

Saran yang penulis dapat dari kesimpulan tersebut, terdapat hal-hal yang disarankan agar penelitian ini dapat berkembang yaitu :

1. Penelitian selanjutnya, agar dapat menambah jumlah data minimal per 2 tahun untuk mendapatkan hasil yang lebih efektif dalam mengelompokkan supplier obat.

2. Dari penelitian ini masih terdapat kekurangan yaitu bedanya hasil yang didapat dari perhitungan manual dengan perhitungan menggunakan tools RapidMiner, diharapkan pada penelitian selanjutnya agar pada perhitungan manual dengan perhitungan menggunakan tools RapidMiner mendapatkan hasil yang sama.

\section{UCAPAN TERIMA KASIH}

Penulis mengucapkan terima kasih kepada Universitas Potensi Utama (UPU) yang telah membimbing serta mendukung penuh terhadap penelitian ini.

\section{DAFTAR PUSTAKA}

[1] Azwir, H. H., \& Pasaribu, E. B. (2017). Pemilihan Supplier Menggunakan Metode Analytic Network Process Di PT UTPE. Jurnal Teknik Industri, 18(2), 103-112.

[2] Fadhli, S. D. (2019). Sistem Informasi Penjualan Dan Persediaan Obat Pada Apotek Sehat Abadi (Doctoral dissertation, Universitas Komputer Indonesia).

[3] Elmayati, E. (2017). Data Mining Dengan Metode Clustering Untuk Pengolahan Informasi Persediaan Obat Pada Klinik Srikandi Medika Berbasis Web. Pelita Informatika: Informasi dan Informatika, 6(2).

[4] Nasari, F., \& Darma, S. (2015). Penerapan k-means clustering pada data penerimaan 
mahasiswa baru (studi kasus: universitas potensi utama). SEMNASTEKNOMEDIA ONLINE, 3(1), 2-1.

[5] Putra, R. R., \& Wadisman, C. (2018). Implementasi Data Mining Pemilihan Pelanggan Potensial Menggunakan Algoritma K Means. INTECOMS: Journal of Information Technology and Computer Science, 1(1), 72-77.

[6] Abdurahman, M. (2018). Sistem Informasi data pegawai berbasis web pada kementerian Kelautan dan Perikanan Kota Ternate. Jurnal Ilmiah ILKOMINFO-Ilmu Komputer \& Informatika, 1(2).

[7] Suryadi, S. (2018). Penerapan Metode Clustering K-means untuk Pengelompokan Kelulusan mahasiswa Berbasis Kompetensi. JURNAL INFORMATIKA, 6(1), 52-72.

[8] Larose, D. T., \& Larose, D. T. (2006). Data mining methods and models (Vol. 12). Hoboken (NJ): Wiley-Interscience.

[9] Azhar, Z., Hutahaean, J., Siagian, Y., \& Syah, A. Z. (2019). Pelatihan Microsoft Excel 2010 Pada Siswa Lembaga Kursus Pendidikan (Lkp) Mandiri. Jurnal Anadara Pengabdian Kepada Masyarakat, 1(2).

[10] Linarwati, M., Fathoni, A., \& Minarsih, M. M. (2016). Studi Deskriptif Pelatihan Dan Pengembangan Sumberdaya Manusia Serta Penggunaan Metode Behavioral Event Interview Dalam Merekrut Karyawan Baru Di Bank Mega Cabang Kudus. Journal of Management, 2(2).

[11] Susanto, A. (2003). Pengenalan Komputer. Ilmu Komputer. Com,(http://nyoman. staf. narotama. ac. id/files/2012/01/arief_pengenalankomputer. pdf), tanggal akses, 7 . 